\title{
CONSÓRCIO SORGO-SOJA. IX. INFLUÊNCIA DE SISTEMAS DE CORTES NA PRODUÇÃO DE FORRAGENS DE SORGO E SOJA CONSORCIADOS NA LINHA E DE SORGO EM MONOCULTIVO
}

\author{
ALESSANDRO GUERRA DA SILVA ${ }^{1}$ \\ PEDRO MILANEZ DE REZENDE ${ }^{2}$ \\ CRISTIANE FORTES GRIS ${ }^{3}$ \\ LEONARDO LINO GOMES ${ }^{3}$ \\ ÉLBERIS PEREIRA BOTREL ${ }^{4}$
}

\begin{abstract}
RESUMO - Visando selecionar em condição de consórcio na linha cultivares de soja e híbridos de sorgo de melhor rendimento forrageiro, foi conduzido um ensaio, em 1997/98, no Departamento de Agricultura no Campus da Universidade Federal de Lavras, em Lavras, MG, em um Latossolo Roxo distrófico. O delineamento experimental utilizado foi o de blocos casualizados, em esquema fatorial $2 \times 4 \times 4+4$ com três repetições, sendo constituído por dois sistemas de corte (um único corte, rente ao solo, do sorgo e soja no estádio $R_{5}$ da soja, e um sistema de dois cortes: o primeiro feito aos 60 dias após a emergência, a $30 \mathrm{~cm}$ do solo e o segundo após a rebrota das plantas, rente ao solo, na mesma época do corte do primeiro sistema); quatro cultivares de soja (CAC-1, Conquista, Cristalina e Doko RC) e quatro hí-
\end{abstract}

bridos de sorgo forrageiro (AG 2002, AG 2005E, BR 601 e Massa 03). Foi realizado um outro ensaio contíguo para o respectivo monocultivo de sorgo, sendo as plantas cortadas no estádio de grãos farináceos. No consórcio, os diferentes sistemas de corte alteraram significativamente os rendimentos de massa verde, matéria seca e proteína bruta total. No consórcio, as cultivares de soja (CAC-1 e Conquista) e os híbridos de sorgo (AG 2002 e BR 601) foram os que mais se destacaram. No sistema consorciado, as associações de melhor performance foram 'CAC-1' x 'BR 601' e 'Conquista' x 'AG 2002' para proteína bruta total e 'Doko' $\mathrm{x}$ 'BR 601' e 'CAC-1' x 'BR 601' para matéria verde total. Em monocultivo, os híbridos AG 2002 e BR 601 apresentaram os maiores rendimentos de massa verde, matéria seca e proteína bruta total.

TERMOS PARA INDEXAÇÃO: Consórcio, matéria seca, proteína bruta, rebrota.

\section{SORGHUM-SOYBEAN INTERCROPPING. IX. CUTTING SYSTEMS ON FORAGE YIELD SORGHUM AND SOYBEAN CULTIVARS INTERCROPPED WITHIN THE LINE AND MONOCULTURE OF SORGHUM}

\begin{abstract}
Seeking to select in intercropping condition in the line of soybean cultivars and sorghum hybrids with better forage yields, a trial was conducted, in 1997/98, at the Agricultural Department of the Federal Universidade of Lavras, Lavras, MG, in a distrofic Dusky Latosol. The experimental design was a randomized block in a factorial scheme $2 \times 4 \times 4+4$ with three replication, consisting of two cutting systems (a
\end{abstract}

single cutting, close to the soil, of both crops at $\mathrm{R}_{5}$ stage of the soybean, and a two cutting system: the first done 60 days after emergence, at $30 \mathrm{~cm}$ from the soil surface and the second after the plants regrowth, close to the soil, at the same time of the cutting of the first system); four soybean cultivars (CAC-1, Conquista, Cristalina and Doko RC) and four hybrids of forage sorghum (AG 2002, AG 2005E, BR 601 and Massa 03). Another

1. Engenheiro Agrônomo, Ms., Pós-graduando do Departamento de Fitotecnia da Universidade Federal de Viçosa, 36570-000 - Viçosa, MG.

2. Engenheiro Agrônomo, D.Sc., Professor Titular do Departamento de Agricultura da UNIVERSIDADE FEDERAL DE LAVRAS/UFLA, Caixa Postal 37, 37200-000 - Lavras, MG (Bolsistas do CNPq).

3. Graduandos do curso de Agronomia da UFLA.

4. Engenheiro Agrônomo, Ms., Pós graduando do Departamento de Agricultura da UFLA. 
contiguous trial was conducted for the respective monoculture of sorghum, being realized the cutting of the plants with grains in mealy stage. In the intercropping, the differents cutting systems showed significant differences in yields, green mass, dry matter and total grude protein. The soybean cultivars (CAC-1 and Conquista) and the sorghum hybrids (AG 2002 and BR 601) were the ones that more stood out. In the intercropped system the combinations of better performance were 'CAC-1' $\mathrm{x}$ 'BR 601' and 'Conquista' $\mathrm{x}$ 'AG 2002' for total grude protein and 'Doko' $x$ 'BR 601' and 'CAC-1' $x$ 'BR 601' for total green mass. In the monoculture the AG 2002 and BR 601 hybrids presented the largerst yields of green mass, dry matter and total grude protein.

INDEX THERMS: Intercropping, dry matter, grude protein, regrowth.

\section{INTRODUÇÃO}

A forma mais usual de utilização da cultura do sorgo na alimentação de ruminantes é via silagem, que constitui um volumoso de bom valor energético, mas deficiente em proteína. O uso de leguminosas nos sistemas consorciados visa a proporcionar aumento no teor de proteína do material ensilado, melhorando a qualidade da silagem.

Baseando-se nesse fundamento, Sood \& Sharma (1992) observaram maior rendimento de massa verde e matéria seca nos sistemas consorciados quando utilizaram a soja em consórcio com plantas de sorgo. Harbers et al. (1992) verificaram também que o uso de silagem, contendo sorgo e soja, pode ser uma boa opção em substituição à silagem de milho, podendo-se obter bons resultados no uso desses alimentos.

No Brasil, as publicações a respeito desse assunto vêm mostrando um avanço no que se refere às técnicas de uso dessa prática, bem como novos arranjos culturais e proporções de misturas, com resultados que levam a crer que a associação de gramínea com a leguminosa para ensilar é promissora (Carneiro \& Rodriguez, 1980; Evangelista, 1986, Oliveira, 1986; 1989 e Rezende, 1995).

Trabalho de pesquisa evidenciando o aspecto favorável de rebrota das duas culturas isoladamente tem sido mencionado por vários pesquisadores (Oliveira, 1989; Rezende \& Takahashi, 1990; Silva, 1998). Em razão dessa capacidade de rebrota, plantas de sorgo e soja poderão fornecer em conjunto no consórcio mais forragem por unidade de área do que o monocultivo da gramínea. As plantas que permanecem no campo irão rebrotar, podendo essa rebrota ser utilizada na forma de forragem ou de grãos, dependendo da necessidade do agricultor. Como essa técnica é muito pouco explorada, há necessidade de maiores informações, principalmente sobre recomendações de cultivares. Dentro desse contexto, com o presente trabalho objetivou-se selecionar materiais de sorgo e soja adequados para produção de forragem em consórcio, submetidos a dois sistemas de corte.

\section{MATERIAL E MÉTODOS}

O trabalho foi instalado no período agrícola de 1997/98, na área experimental da UFLA (Departamento de Agricultura) em Lavras, MG, localizada na latitude de $21^{\circ} 14^{\prime} \mathrm{S}$, longitude $45^{\circ} 00^{\prime} \mathrm{W}$ e altitude de $918 \mathrm{~m}$. As variações diárias da temperatura média e da distribuição de chuvas durante a condução do ensaio encontram-se na Figura 1.

O delineamento experimental foi o de blocos casualizados com três repetições em esquema fatorial $2 \times 4 \times 4+4$, constituído por dois sistemas de corte, quatro cultivares de soja (CAC-1, Conquista, Cristalina e Doko $\mathrm{RC})$ consorciadas na linha com quatro híbridos de sorgo forrageiro (AG 2002, AG 2005E, BR 601 e Massa 03). Esses materiais foram avaliados em todas as combinações possíveis em dois sistemas de corte, sendo as épocas de corte determinadas em função da cultura da soja. No primeiro sistema, as plantas de ambas as espécies foram cortadas uma única vez, rente ao solo, quando as plantas de soja atingiram o estádio $\mathrm{R}_{5}$ (início da formação da semente), de acordo com Fehr \& Caviness (1977). No segundo sistema, ambas as culturas foram cortadas duas vezes, sendo o primeiro corte realizado à altura de $30 \mathrm{~cm}$ do colo das plantas aos 60 dias após emergência, e o segundo corte após a rebrota, rente ao solo, na mesma época do corte do primeiro sistema (estádio $\mathrm{R}_{5}$ ). Adicionalmente foi conduzido outro ensaio contíguo em blocos casualizados com três repetições para monocultivo de sorgo, sendo o corte realizado no estádio farináceo uma única vez rente ao solo.

Tanto no monocultivo como no consórcio, as parcelas de sorgo foram constituídas por três linhas espaçadas de 0,8 m entre si, com 5,0 m de comprimento, sendo considerada como área útil apenas a fileira central $\left(4,0 \mathrm{~m}^{2}\right)$. Para a cultura da soja, foi utilizado o sistema de consórcio na linha do sorgo, utilizando também uma linha como área útil. $\mathrm{O}$ desbaste foi realizado aos 25 dias após a emergência das plântulas, procurando-se manter 12 plantas por metro linear para a cultura do sorgo e soja (150.000 plantas/ha) no consórcio e também no monocultivo de sorgo.

Ciênc. agrotec., Lavras. V.27, n.2, p.451-461, mar./abr., 2003 
Para o sorgo, em condição de consórcio e monocultivo, a calagem e adubação seguiram as recomendações feitas pela Comissão... (1989), utilizando-se o correspondente a $20 \mathrm{~kg}$ de $\mathrm{N}, 120 \mathrm{~kg}$ de $\mathrm{P}_{2} \mathrm{O}_{5}$ e $120 \mathrm{~kg}$ de $\mathrm{K}_{2} \mathrm{O} /$ ha. Aos 30 e 45 dias após emergência das plântulas, no consórcio e monocultivo, aplicaram-se $60 \mathrm{~kg}$ de $\mathrm{N} / \mathrm{ha}$ em cobertura. No caso do consórcio, a cultura da soja não foi adubada, utilizando-se apenas a adubação recomendada para o sorgo forrageiro nas mesmas dosagens do monocultivo de sorgo.

Antes da semeadura, realizada em 15/10/97, foi feita a inoculação das sementes de soja com Bradyrhizobium japonicum, utilizando o inoculante turfoso, na proporção de $200 \mathrm{~g}$ de inoculante para $50 \mathrm{~kg}$ de sementes. As parcelas foram mantidas livres de invasoras, sendo realizadas duas capinas manuais.

TABELA 1 - Resultados das análises químicas da amostra de solo coletada na profundidade de 0-20 cm na área experimental, UFLA, Lavras (MG), 1997. ${ }^{1}$

\begin{tabular}{ccc}
\hline Determinações & Valores & Classificação** \\
\hline $\mathrm{PH}$ em água & 6,2 & Ac. Fraca \\
$\mathrm{P}\left(\mathrm{mg} / \mathrm{dm}^{3}\right)$ & 11,0 & Médio \\
$\mathrm{K}\left(\mathrm{mg} / \mathrm{dm}^{3}\right)$ & 22,0 & Baixo \\
$\mathrm{Ca}\left(\mathrm{cmolc} / \mathrm{dm}^{3}\right)$ & 4,6 & Alto \\
$\mathrm{Mg}\left(\mathrm{cmolc} / \mathrm{dm}^{3}\right)$ & 0,1 & Baixo \\
$\mathrm{Al}\left(\mathrm{cmolc} / \mathrm{dm}^{3}\right)$ & 0,0 & Baixo \\
$\mathrm{H}+\mathrm{Al}\left(\mathrm{cmolc} / \mathrm{dm}^{3}\right)$ & 3,2 & Médio \\
$\mathrm{S}\left(\mathrm{cmolc} / \mathrm{dm}^{3}\right)$ & 4,8 & Médio \\
$\mathrm{t}\left(\mathrm{cmolc} / \mathrm{dm}^{3}\right)$ & 4,8 & Médio \\
$\mathrm{T}\left(\mathrm{cmolc} / \mathrm{dm}^{3}\right)$ & 8,0 & Médio \\
$\mathrm{m}(\%)$ & 0,0 & Baixo \\
$\mathrm{v}(\%)$ & 60,0 & Médio \\
Mat. Org. $\left(\mathrm{dag} / \mathrm{dm}^{3}\right)$ & 2,1 & Médio \\
\hline
\end{tabular}

*Análises realizadas no Instituto de Química "John H. Wheelock" do Departamento de Ciências do Solo da Universidade Federal de Lavras, Lavras (MG).

**Interpretação dos resultados de acordo com a Comissão de Fertilidade do Solo do Estado de Minas Gerais (1989).

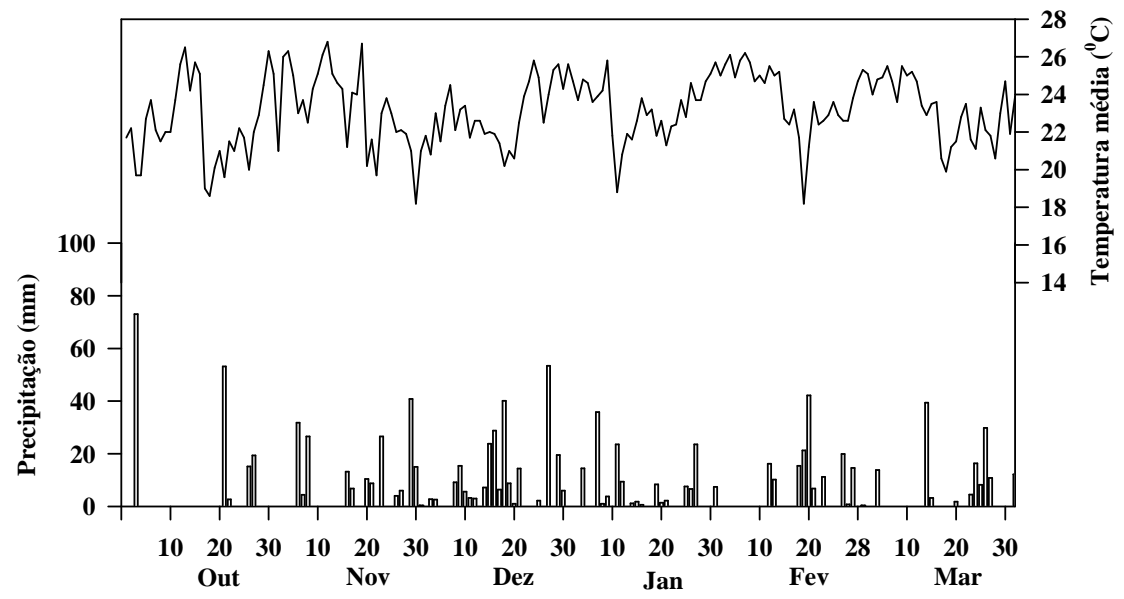

FIGURA 1 - Variação diária da temperatura média do ar e precipitação pluvial de outubro de 1997 a abril de 1998 , UFLA, Lavras (MG) - (FONTE: ESTAÇÃO CLIMATOLÓGICA DE LAVRAS - MG). 
O corte das plantas de soja e sorgo foi realizado manualmente com o auxílio de roçadeira costal motorizada nas épocas já relatadas anteriormente. Os materiais foram pesados, separando-se o sorgo da soja, sendo analisado o rendimento de massa verde $\left(\mathrm{kg} \cdot \mathrm{ha}^{-1}\right)$ e matéria seca, determinado em amostra de $200 \mathrm{~g}$ de massa verde em estufa a $65^{\circ} \mathrm{C}$ até peso constante e convertido em $\mathrm{kg} \cdot \mathrm{ha}^{-1}$ ) e proteína bruta, determinada na mesma amostra usada na matéria seca, utilizando-se o método Kjeldahl de acordo com metodologia descrita por Malavolta et al. (1989), transformando-se, posteriormente, os dados para kg.ha-1.

As análises estatísticas foram realizadas para as características citadas anteriormente, utilizando-se o somatório das duas culturas (sorgo + soja). Para diferenciação das médias, foi utilizado o teste de Duncan a $5 \%$ e os resultados obtidos foram comparados com os respectivos monocultivos de sorgo dentro de cada sistema de corte, pelo teste " $\mathrm{t}$ " de contraste.

\section{RESULTADOS E DISCUSSÃO}

\section{Rendimento de Massa Verde}

As variáveis sistemas de corte, cultivares de soja, híbridos de sorgo, interação corte x soja e monocultivo foram significativas a $1 \%$ de probabilidade (Tabela 2).

Levando-se em consideração a média dos dois sistemas de corte no cultivo consorciado, pode-se observar um acréscimo de 28,43\% (12.888 kg.ha $\left.{ }^{-1}\right)$ a favor do sistema de dois cortes, o que pode ser devido à época de semeadura (15/10) e também à capacidade de rebrota das plantas de soja e sorgo (Tabela 3). Resultados contrários foram observados por Silva (1998), que obteve $9,98 \%$ de acréscimo no rendimento de massa verde de sorgo e soja no sistema de um corte, o que foi atribuído à baixa capacidade de rebrota de ambas as culturas, que pode ter ocorrido em conseqüência da época de semeadura mais avançada. Com relação à cultura da soja, Rezende \& Takahashi (1990) obtiveram aumento de 19\%, em condição de monocultivo, quando as cultivares foram semeadas e cortadas em época semelhante ao do presente trabalho. Torna-se importante ressaltar que o rendimento de forragem de sorgo e soja é aumentado com antecipação da época de semeadura, principalmente quando é realizado no início do mês de outubro, proporcionando maior facilidade de rebrota de ambas as culturas.

As cultivares de soja utilizadas proporcionaram diferenças significativas nos rendimentos de massa verde total, podendo-se observar dois grupos distintos, no qual a 'CAC-1' e 'Conquista' superaram as cultivares Cristalina e Doko RC (Tabela 3). Com relação aos híbridos de sorgo, pode-se observar uma performance diferenciada do híbrido AG 2002 no rendimento final (70.177 kg.ha ${ }^{-1}$ de massa verde, na média dos dois sistemas de corte), superando em 101,28\% (35.312 kg.ha- ${ }^{-1}$ o híbrido Massa 03, de menor rendimento. Essa grande diferença pode ser explicada pelo porte dos híbridos de sorgo, pois o 'Massa 03' apresenta porte menor, sendo utilizado para triplo propósito (silagem, grãos e palhada para plantio direto). Por outro lado, o híbrido AG 2002, sendo considerado de porte alto, proporcionou maior rendimento de forragem, havendo maior contribuição por parte da gramínea.

Quando se desdobra a interação corte x soja, observa-se uma superioridade no rendimento final de forragem com o uso das cultivares CAC-1 e Conquista dentro do sistema de um corte 52.354 e $52.437 \mathrm{~kg}^{-h^{-1}}{ }^{-1}$, respectivamente, o mesmo não se verificando no sistema de dois cortes, que não apresentou diferenças significativas. Por outro lado, estudando-se o efeito de cada cultivar dentro dos dois sistemas de corte, verifica-se que todas as cultivares apresentaram maior rendimento no sistema de dois cortes, com destaque para 'Doko' e 'Cristalina' que, proporcionalmente, apresentaram maiores aumentos no rendimento, com 54,94\% (21459 kg.ha $\left.{ }^{-1}\right)$ e $49,58 \%$ (18573 kg.ha $\left.{ }^{-1}\right)$ em relação ao sistema de único corte.

Apesar de não ter sido constatada significância para a fonte de variação consórcio vs. monocultivo (Tabela 2), pode-se observar no sistema de um único corte rendimento significativamente inferior no consórcio com a combinação da cultivar Cristalina com os híbridos AG 2002, AG 2005E e BR 601 e da Doko RC com o BR 601, em relação aos respectivos monocultivo de sorgo (Tabela 3). Por outro lado, no sistema de dois cortes, pode-se verificar acréscimo médio de $33,13 \%$ (14.487 kg.ha $\left.{ }^{-1}\right)$ a favor do consórcio. À exceção das associações do híbrido AG 2002 com todas as cultivares de soja e da 'Cristalina' com o 'AG 2005E', todas as demais combinações, no sistema de dois cortes, superaram os respectivos monocultivo de sorgo. Destaque maior deve ser dado à associação do híbrido BR 601 consorciado com as cultivares Doko RC, CAC-1 e Conquista no sistema de dois cortes, que proporcionaram os maiores acréscimos nos rendimentos $(29.666,22.666 \mathrm{e}$ 22.541), respectivamente. Esses acréscimos no rendimento do cultivo consorciado no sistema de dois cortes pode, provavelmente, estar associado à capacidade de rebrota das duas culturas. 
TABELA 2 - Resumo da análise de variância combinada das características rendimento de massa verde, matéria seca e proteína bruta de sorgo + soja em relação ao monocultivo de sorgo obtidas no ensaio de avaliação de cultivares de sorgo e soja em consórcio e monocultivo visando à produção de forragem, UFLA, Lavras (MG), 1997/98.

\begin{tabular}{|c|c|c|c|c|}
\hline \multirow{2}{*}{ F.V. } & \multirow{2}{*}{ G.L. } & \multicolumn{3}{|c|}{ Quadrados Médios } \\
\hline & & Massa Verde & Matéria Seca & Proteína Bruta \\
\hline Consórcio & 31 & $993.987 .562 * *$ & $52.761 .452 * *$ & $477.984 * *$ \\
\hline Corte & 1 & $3.986 .425 .944 * *$ & $362.532 .720 * *$ & $4.773 .984 * *$ \\
\hline Soja & 3 & $430.636 .013^{* *}$ & 13.701 .657 & $1.618 .034 * *$ \\
\hline Sorgo & 3 & $7.804 .899 .468 * *$ & $286.048 .107 * *$ & $1.152 .542 * *$ \\
\hline Soja x Sorgo & 9 & 31.849 .555 & 6.430 .678 & 64.634 \\
\hline Corte x Soja & 3 & $415.138 .184 * *$ & $54.552 .792 * *$ & 46.131 \\
\hline Corte x Sorgo & 3 & 60.958 .930 & $33.354 .109 * *$ & 73.121 \\
\hline Corte $\mathrm{x}$ Soja x Sorgo & 9 & 45.071 .633 & 5.802 .911 & 88.036 \\
\hline Monocultivo & 3 & $1.242 .269 .097 * *$ & $107.142 .256^{* *}$ & $175.194 * * *$ \\
\hline Consorcio vs Monocult. & 1 & 18.925 .936 & $38.312 .716^{*}$ & $372.422 *$ \\
\hline Erro Médio & 68 & 77.725 .639 & 6.113 .756 & 75.185 \\
\hline $\mathrm{CV}(\%)$ & & 16,98 & 17,17 & 19,21 \\
\hline
\end{tabular}

***ignificativo 1\%; * Significativo $5 \%$, *** Significativo a $8,0 \%$.

À semelhança do que ocorreu no consórcio, também no monocultivo o destaque foi para o híbrido AG 2002 e BR 601, que proporcionaram aumento no rendimento de $90,51 \%$ (35000 kg.ha' $\left.{ }^{-1}\right) ; 124,36 \%$ (40834 kg.ha $\left.{ }^{-1}\right)$ e $73,92 \%$ (28583 kg.ha $\left.{ }^{-1}\right)$ e $104,82 \%$ (34417 kg.ha ${ }^{-1}$ ) em relação aos híbridos AG 2005E e Massa 03, respectivamente. É importante ressaltar que o porte mais baixo e o caráter de utilização desses híbridos como duplo propósito (AG 2005E) ou triplo propósito (Massa 03) condicionaram menor rendimento de forragem em relação ao 'AG 2002' e 'BR 601'. Em consequiência das adequadas condições de cultivo, da semeadura realizada na primeira quinzena de outubro e da ausência de veranicos, os resultados obtidos nessa condição de cultivo são superiores aos obtidos por Casela et al. (1986), Costa \& Azevedo (1996) e Silva (1998).

\section{Rendimento de Matéria Seca Total}

Essa característica foi influenciada significativamente pelos sistemas de corte, híbridos de sorgo, interação corte $\mathrm{x}$ soja e corte $\mathrm{x}$ sorgo, monocultivo e consórcio vs monocultivo. (Tabela 2 ).
A utilização do sistema de um único corte no cultivo consorciado, ao contrário do rendimento de massa verde, superou em 31,72\% (3.886 kg.ha' $\left.{ }^{-1}\right)$ o sistema de dois cortes (Tabela 4). Esse fato pode ser explicado pelas épocas de corte, pois, no sistema de dois cortes, as culturas da soja do sorgo foram colhidas com alto grau de umidade. No momento do segundo corte nas cultivares CAC-1 e Conquista, os híbridos AG 2002 e BR 601, consorciados com essas cultivares de soja, encontravam-se no início do estádio de emissão da panícula e/ou emborrachamento, e os híbridos AG 2005E e Massa 03, no início do estádio de grãos leitosos e/ou farináceo. Por outro lado, quando se realizou o segundo corte das cultivares Cristalina e Doko RC, os híbridos AG 2002 e BR 601 encontravam-se no estádio de grãos farináceos, e os híbridos AG 2005E e Massa 03, em estádio de grãos farináceo duro. Silva (1998) também encontrou acréscimos $(41,35 \%)$ no rendimento de matéria seca no sistema de um corte, quando realizou o consórcio sorgo-soja. Os valores obtidos por esse autor, nos dois sistemas de corte, são inferiores aos obtidos neste ensaio, o que pode ser conseqüência da época de semeadura já relatada anteriormente. 
TABELA 3 - Resultados médios de massa verde de sorgo e soja $\left(\mathrm{kg}_{\text {.ha }}{ }^{-1}\right)$ obtidos no ensaio de avaliação de cultivares de sorgo e soja em consórcio e monocultivo visando à produção de forragem, UFLA, Lavras (MG),1997/98.

\begin{tabular}{lccc}
\hline \multicolumn{1}{c}{ Tratamentos } & Sist. de Um Corte & Sist. de Dois Cortes & Média \\
\hline CAC-1 x AG 2002 & 70.917 & 72.667 & 71.792 \\
CAC-1 x AG 2005E & 38.333 & $47.958^{*}$ & 43.146 \\
CAC-1 x BR 601 & 65.417 & $70.833^{* *}$ & 68.125 \\
CAC-1 x Massa 03 & 34.750 & $39.750^{*}$ & 37.250 \\
Conquista x AG 2002 & 70.167 & 71.667 & 70.917 \\
Conquista x AG 2005E & 32.583 & $48.417^{*}$ & 40.500 \\
Conquista x BR 601 & 66.417 & $70.708^{* *}$ & 68.562 \\
Conquista x Massa 03 & 40.583 & $43.250^{* *}$ & 41.917 \\
Cristalina x AG 2002 & $55.917^{* *}$ & 78.667 & 67.292 \\
Cristalina x AG 2005E & $22.833^{*}$ & 41.500 & 32.167 \\
Cristalina x BR 601 & $48.750^{* *}$ & $67.042^{* *}$ & 57.896 \\
Cristalina x Massa 03 & 22.333 & $36.917^{*}$ & 29.625 \\
Doko RC x AG 2002 & 58.500 & 82.917 & 70.708 \\
Doko RC x AG 2005E & 26.000 & $44.750^{*}$ & 35.375 \\
Doko RC x BR 601 & $47.000^{* *}$ & $77.833^{* *}$ & 62.417 \\
Doko RC x Massa 03 & 24.750 & $36.583^{*}$ & 30.667 \\
\hline CAC-1 x Sorgo & $52.354 \mathrm{~A}$ a & $57.802 \mathrm{~A} \mathrm{a}$ & $55.078 \mathrm{a}$ \\
Conquista x Sorgo & $52.437 \mathrm{~A}$ a & $58.510 \mathrm{~A} \mathrm{a}$ & $55.474 \mathrm{a}$ \\
Cristalina x Sorgo & 37.458 B b & $56.031 \mathrm{~A} \mathrm{a}$ & $46.745 \mathrm{~b}$ \\
Doko RC x Sorgo & 39.062 B b & $60.521 \mathrm{~A} \mathrm{a}$ & $49.792 \mathrm{~b}$ \\
\hline AG 2002 x Soja & 63.875 & 76.479 & $70.177 \mathrm{a}$ \\
AG 2005E x Soja & 29.937 & 45.656 & $37.797 \mathrm{c}$ \\
BR 601 x Soja & 56.896 & 71.604 & $64.250 \mathrm{~b}$ \\
Massa 03 x Soja & 30.604 & 39.125 & $34.865 \mathrm{c}$ \\
\hline Média & 45.328 B & $58.216 \mathrm{~A}$ & 51.772 \\
\hline Monocultivo & 73.667 a & & \\
\hline AG 2002 & 38.667 b & & \\
AG 2005E & $67.250 \mathrm{a}$ & & \\
BR 601 & $32.833 \mathrm{~b}$ & & \\
Massa 03 & $53.104 \mathrm{~A}$ & & \\
\hline Média & & & \\
\hline & Medias segidas pea mesma & \\
\hline
\end{tabular}

* Médias seguidas pela mesma letra minúscula na coluna e maiúscula na linha não diferem entre si pelo teste de Duncan a $5 \%$ de probabilidade.

** Significativo a $1 \%$ e * Significativo a $5 \%$ em relação ao monocultivo do sorgo pelo teste de 't $t$ '.

Ciênc. agrotec., Lavras. V.27, n.2, p.451-461, mar./abr., 2003 
Em se tratando do teor de matéria seca presente na forragem, pode-se observar no momento do corte que o teor médio das cultivares de soja e híbridos de sorgo no sistema de um corte foi de $35,60 \%$, valor recomendado para a prática de ensilagem (Pupo, 1995), e no sistema de dois cortes, esse valor foi de $21,04 \%$, valor esse inferior em $14,56 \%$ ao observado no sistema de único corte. $\mathrm{O}$ corte aos 60 dias após a emergência das plântulas e os estádios em que os híbridos de sorgo encontravam-se no momento do segundo corte do sistema de dois cortes proporcionou queda no rendimento de matéria seca total em relação ao primeiro sistema, quando as plantas foram cortadas rente ao solo uma única vez no estádio $R_{5}$ da soja.

A utilização de híbridos de sorgo de ciclos e portes diferentes resultaram em rendimentos diferenciados de matéria seca total. Semelhante ao rendimento de massa verde, o híbrido AG 2002 no sistema consorciado apresentou rendimento de $18.123 \mathrm{~kg} \cdot \mathrm{ha}^{-1}$, na média dos dois sistema de corte, diferindo, dessa forma, dos demais (Tabela 4). A performance inferior com os híbridos AG 2005E e Massa 03 (11.672 e 10.943 kg.ha ${ }^{-1}$, respectivamente), deve-se ao fato de esses materiais serem de porte inferior ao 'AG 2002' e 'BR 601', proporcionando menor rendimento de forragem. $\mathrm{Na}$ avaliação do rendimento do cultivo consorciado, esses resultados já eram esperados, pois houve maior contribuição por parte da gramínea no rendimento total.

Apesar de não ter sido constatada significância para a fonte de variação cultivares de soja, foi detectada significância para a interação corte x soja (Tabela 2). Analisando as cultivares de soja dentro de cada sistema de corte, verifica-se que no sistema de um corte a utilização das cultivares CAC-1 e Conquista proporcionaram rendimentos de 18.164 e 17.795 kg.ha ${ }^{-1}$ respectivamente, sendo esses valores superiores ao das cultivares Cristalina e Doko RC (Tabela 4). No sistema de dois cortes, a utilização da cultivar Doko RC, proporcionou o maior rendimento (13.647 kg.ha ${ }^{-1}$ ) e a pior performance foi observada com a 'CAC-1'. Por outro lado, analisando as cultivares dentro dos sistemas de cortes, verificou-se que os maiores rendimentos foram observados no sistema de um único corte com destaque para 'CAC-1' e 'Conquista', que proporcionaram rendimentos de $60,53 \%\left(6849 \mathrm{~kg} \mathrm{ha}^{-1}\right)$ e $52,19 \%\left(6102 \mathrm{~kg}^{-\mathrm{ha}^{-1}}\right)$ superiores ao de dois cortes. Esse maior valor observado no sistema de um corte, conforme relatado anteriormente, é devido à maior contribuição dos híbridos de sorgo, quando consorciado com as cultivares CAC-1 e Conquista, e também às diferenças de umidade nos ma- teriais cortados verificados em função dos cortes, já relatados anteriormente.

A interação corte x sorgo, depois de desdobrada, considerando cada híbrido dentro dos sistemas de corte, indicou uma melhor performance dos híbridos AG 2002, BR 601 e Massa 03 no sistema de um único corte (Tabela 4). Por outro lado, observando o efeito dos híbridos de sorgo dentro de cada sistema de corte, verifica-se uma performance superior do híbrido AG 2002 $\left(21.432 \mathrm{~kg} \cdot \mathrm{ha}^{-1}\right)$, diferindo-se dos demais no sistema de um único corte. Já no sistema de dois cortes, o rendimento com os híbridos AG 2002 e BR 601 foram semelhantes (14.815 e $13.842 \mathrm{~kg} \cdot \mathrm{ha}^{-1}$, respectivamente) e superiores ao do 'AG 2005E' e 'Massa 03', que diferiram entre si. Rezende (1995), trabalhando com o consórcio milho-soja, obteve rendimentos de matéria seca total variando de 11.404 a $17.835 \mathrm{~kg} . \mathrm{ha}^{-1}$, valores esses inferiores aos obtidos com os híbridos AG 2002 e BR 601 utilizados neste ensaio.

Em condição de monocultivo, à semelhança do que ocorreu com a massa verde, pode-se observar que os híbridos de maior porte (AG 2002 e BR 601) apresentaram os maiores rendimentos de matéria seca, superando o 'AG 2005E' em 84,46\% (10015 kg.ha ${ }^{-1}$ ) e $73,94 \%$ (8746 kg.ha $\left.{ }^{-1}\right)$ e a Massa 03 em 116,07\% $\left(10015\right.$ kg.ha $\left.{ }^{-1}\right)$ e $103,52 \%$ (10465 kg.ha $\left.{ }^{-1}\right)$, respectivamente.

Apesar de os resultados dos híbridos de porte médio assemelharem-se aos de Costa e Azevedo (1996), os valores obtidos com os híbridos AG 2002 e BR 601 são superiores aos encontrados por esses autores e aos de Liseu (1981), Pereira (1991) e Silva (1998).

\section{Rendimento de Proteína Bruta Total}

$\mathrm{Na}$ análise dessa característica, constatou-se significância para as fontes de variação: sistemas de cortes, cultivares de soja, híbridos de sorgo e consórcio vs. monocultivo (Tabela 2).

Como pode-se observar na Tabela 5, para o cultivo em consórcio, verifica-se uma superioridade de $36,41 \%$ (446 kg.ha ${ }^{-1}$ ) de proteína bruta total no sistema de dois cortes em relação ao primeiro sistema. Esse resultado é explicado, em grande parte, pelo rendimento das cultivares de soja, que apresentaram boa rebrota, contribuindo para o rendimento final. $\mathrm{O}$ rendimento obtido com as combinações de sorgo e soja são superiores aos observados por Silva (1998), que obteve acréscimo de $13,92 \%$ a favor do sistema de dois cortes na cultura do sorgo e soja. 
TABELA 4 - Resultados médios de matéria seca de sorgo e soja $\left(\mathrm{kg}_{\text {gha }}{ }^{-1}\right)$ obtidos no ensaio de avaliação de cultivares de sorgo e soja em consórcio e monocultivo visando à produção de forragem, UFLA, Lavras (MG), $1997 / 98$.

\begin{tabular}{|c|c|c|c|}
\hline Tratamentos & Sist. de Um Corte & Sist. de Dois Cortes & Média \\
\hline CAC-1 x AG 2002 & 23.124 & $12.455^{\mathrm{NS}}$ & 17.789 \\
\hline CAC-1 x AG 2005E & 14.771 & $11.374^{\mathrm{NS}}$ & 13.072 \\
\hline CAC-1 x BR 601 & 20.771 & $12.625^{\mathrm{NS}}$ & 16.698 \\
\hline CAC-1 x Massa 03 & 13.992 & 8.805 & 11.399 \\
\hline Conquista x AG 2002 & 21.364 & 13.134 & 17.249 \\
\hline Conquista x AG 2005E & 12.363 & 11.462 & 11.912 \\
\hline Conquista x BR 601 & 21.767 & 12.372 & 17.070 \\
\hline Conquista x Massa 03 & $15.688 * *$ & 9.803 & 12.745 \\
\hline Cristalina x AG 2002 & 20.76 & 15.511 & 18.138 \\
\hline Cristalina x AG 2005E & 9.458 & 10.464 & 9.961 \\
\hline Cristalina x BR 601 & $15.350 *$ & $14.485^{*}$ & 14.917 \\
\hline Cristalina x Massa 03 & 10.169 & 8.919 & 9.544 \\
\hline Doko RC x AG 2002 & 20.473 & 18.160 & 19.317 \\
\hline Doko RC x AG 2005E & 11.895 & 11.587 & 11.741 \\
\hline Doko RC x BR 601 & $15.017 * *$ & 15.887 & 15.452 \\
\hline Doko RC x Massa 03 & 11.217 & 8.956 & 10.086 \\
\hline CAC-1 x Sorgo & $18.164 \mathrm{~A} \mathrm{a}$ & 11.315 B b & 14.739 \\
\hline Conquista $\mathrm{x}$ Sorgo & $17.795 \mathrm{~A} \mathrm{a}$ & $11.693 \mathrm{~B} \mathrm{ab}$ & 14.744 \\
\hline Cristalina x Sorgo & $13.936 \mathrm{~A} \quad \mathrm{~b}$ & $12.345 \mathrm{~A} \quad \mathrm{ab}$ & 13.140 \\
\hline Doko RC x Sorgo & $14.650 \mathrm{~A} \quad \mathrm{~b}$ & $13.647 \mathrm{~A} \quad \mathrm{a}$ & 14.149 \\
\hline AG 2002 x Soja & $21.432 \mathrm{~A} \mathrm{a}$ & $14.815 \mathrm{~B} \mathrm{a}$ & $18.123 \mathrm{a}$ \\
\hline AG 2005E x Soja & $12.122 \mathrm{~A} \quad \mathrm{c}$ & $11.221 \mathrm{~A} \quad \mathrm{~b}$ & $11.672 \mathrm{c}$ \\
\hline BR 601 x Soja & $18.226 \mathrm{~A} \quad \mathrm{~b}$ & $13.842 \mathrm{~B} \mathrm{a}$ & $16.034 \mathrm{~b}$ \\
\hline Massa 03 x Soja & $12.766 \mathrm{~A} \quad \mathrm{c}$ & $9.120 \quad \mathrm{~B} \quad \mathrm{c}$ & $10.943 \mathrm{c}$ \\
\hline Média & $16.136 \mathrm{~A}$ & $12.250 \mathrm{~B}$ & 14.193 \\
\hline \multicolumn{4}{|l|}{ Monocultivo } \\
\hline AG 2002 & $21.843 \mathrm{a}$ & & \\
\hline AG $2005 \mathrm{E}$ & $11.828 \mathrm{~b}$ & & \\
\hline BR 601 & $20.574 \mathrm{a}$ & & \\
\hline Massa 03 & $10.109 \mathrm{~b}$ & & \\
\hline Média & 16.088 & & \\
\hline
\end{tabular}

* Médias seguidas pela mesma letra minúscula na coluna e maiúscula na linha não diferem entre si pelo teste de Duncan a $5 \%$ de probabilidade.

** Significativo a $1 \%$ e $*$ Significativo a $5 \%$ em relação ao monocultivo do sorgo pelo teste de ' $t$ '.

Ciênc. agrotec., Lavras. V.27, n.2, p.451-461, mar./abr., 2003 
TABELA 5 - Resultados médios de proteína bruta de sorgo e soja $\left(\mathrm{kg}_{\text {.ha }}{ }^{-1}\right)$ obtidos no ensaio de avaliação de cultivares de sorgo e soja em consórcio e monocultivo visando à produção de forragem, UFLA, Lavras (MG),1997/98.

\begin{tabular}{lccc}
\hline \multicolumn{1}{c}{ Tratamento } & Sist. de Um Corte & Sist. de Dois Cortes & Média \\
\hline CAC-1 x AG 2002 & 1.654 & 1.863 & 1.759 \\
CAC-1 x AG 2005E & 1.267 & $1.890^{* *}$ & 1.579 \\
CAC-1 x BR 601 & 1.787 & $2.194^{* *}$ & 1.991 \\
CAC-1 x Massa 03 & 1.294 & $1.333^{* *}$ & 1.314 \\
Conquista x AG 2002 & 1.509 & $2.192^{* *}$ & 1.851 \\
Conquista x AG 2005E & 1.111 & $1.913^{* *}$ & 1.512 \\
Conquista x BR 601 & 1.810 & $1.956^{* *}$ & 1.883 \\
Conquista x Massa 03 & 1.358 & $1.563^{* *}$ & 1.461 \\
Cristalina x AG 2002 & 1.159 & 1.431 & 1.295 \\
Cristalina x AG 2005E & 797 & 1.309 & 1.053 \\
Cristalina x BR 601 & $956^{*}$ & $1.587^{*}$ & 1.272 \\
Cristalina x Massa 03 & 776 & $1.309^{* *}$ & 1.042 \\
Doko RC x AG 2002 & 1.235 & 1.847 & 1.541 \\
Doko RC x AG 2005E & 1.111 & 1.446 & 1.278 \\
Doko RC x BR 601 & 1.077 & $1.779^{* *}$ & 1.428 \\
Doko RC x Massa 03 & 699 & 1.125 & 912 \\
\hline CAC-1 x Sorgo & 1.501 & 1.820 & $1.660 \mathrm{a}$ \\
Conquista x Sorgo & 1.447 & 1.906 & $1.677 \mathrm{a}$ \\
Cristalina x Sorgo & 922 & 1.409 & $1.165 \mathrm{~b}$ \\
Doko RC x Sorgo & 1.031 & 1.549 & $1.290 \mathrm{~b}$ \\
\hline AG 2002 x Soja & 1.389 & 1.833 & $1.611 \mathrm{a}$ \\
AG 2005E x Soja & 1.072 & 1.639 & $1.355 \mathrm{~b}$ \\
BR 601 x Soja & 1.408 & 1.879 & $1.643 \mathrm{a}$ \\
Massa 03 x Soja & 1.032 & 1.333 & $\mathrm{c}$ \\
\hline Média & 1.225 B & $1.671 \mathrm{~A}$ & \\
\hline Monocultivo & & & \\
\hline AG 2002 & $1.439 \mathrm{a}$ & & \\
AG 2005E & $1.222 \mathrm{~b}$ & & \\
BR 601 & $1.449 \mathrm{a}$ & & \\
Massa 03 & $935 \mathrm{~b}$ & & \\
\hline Média & 1.261 & & \\
\hline & & & \\
\hline
\end{tabular}

* Médias seguidas pela mesma letra minúscula na coluna e maiúscula na linha não diferem entre si pelo teste de Duncan a $5 \%$ de probabilidade.

** Significativo a $1 \%$ e $*$ Significativo a $5 \%$ em relação ao monocultivo do sorgo pelo teste de 't'.

Ciênc. agrotec., Lavras. V.27, n.2, p.451-461, mar./abr., 2003 
As cultivares de soja CAC - 1 e Conquista apresentaram na média dos dois sistemas de corte maiores valores de proteína bruta total, ao passo que para o sorgo, os melhores resultados dessa variável foram obtidos com os híbridos BR 601 e AG 2002, que superaram o 'AG 2005E' em 21,12\% (288 kg.ha ${ }^{-1}$ ) e 18,89\% (256 kg.ha' $\left.{ }^{-1}\right)$ e o 'Massa 03' em 39,00\% (461 kg.ha-1 ) e $36,29 \%$ (429 kg.ha- ${ }^{-1}$ ), respectivamente, conforme pode-se verificar na Tabela 5.

Ao contrário do que ocorreu com o rendimento de matéria seca total para a proteína bruta tota, a contribuição do consórcio é relevante. Nesse sistema, em média, o consórcio superou o monocultivo em 14,82\% (187 kg.ha-1), o que concorda com Silva (1998) que, nessa mesma localidade, constatou aumento nessa característica em função do consórcio. Quando se compara o rendimento de todas as associações de sorgo e soja nos dois sistemas de cortes, verifica-se que todas elas proporcionaram maiores rendimentos no sistema de dois cortes. Esse maior rendimento é atribuído em sua maior parte às cultivares de soja, em função da sua rebrota, melhorando o valor nutritivo da forragem, como é destacado por vários autores (Rezende, 1984; Rezende \& Takarashi, 1990). Analisando as associações dentro do sistema de dois cortes com os respectivos monocultivos do sorgo, verifica-se que essas sempre foram superiores ao respectivo monocultivo, à exceção da associação 'Cristalina' x 'AG 2002' que, embora não significativa, apresentou rendimento inferior no consórcio (1431 kg.ha- ${ }^{-1}$ ) quando comparado ao monocultivo (1439 kg.ha- ${ }^{-1}$ ). Nessa condição, as associações de maior destaque foram 'CAC-1' $\mathrm{x}$ 'BR 601' e 'Conquista' $x$ 'AG 2002', que superaram o monocultivo em 51,41\% (745 kg.ha-1) e 52,32\% (753 kg.ha-1). Trabalhos conduzidos por outros pesquisadores (Carneiro e Rodriguez, 1980; Evangelista, 1986; Oliveira, 1986; Oliveira, 1989; Sood e Sharma, 1992 e Silva, 1998) têm evidenciado também o efeito benéfico dessa associação.

\section{CONCLUSÕES}

a) No consórcio, os diferentes sistemas de corte alteraram significativamente os rendimentos de massa verde, matéria seca e proteína bruta total.

b) No sistema consorciado, as associações de melhor performance foram 'CAC-1' $\mathrm{x}$ ' $\mathrm{BR}$ 601' $\mathrm{e}$ 'Conquista' x 'AG 2002', para proteína bruta total, e 'Doko' x 'BR 601' e 'CAC-1' x 'BR 601', para massa verde total. c) Os híbridos AG 2002 e BR 601 em monocultivo apresentaram os maiores rendimentos de massa verde, matéria seca e proteína bruta total.

\section{REFERÊNCIAS BIBLIOGRÁFICAS}

CARNEIRO, A. M.; RODRIGUEZ, N. M. Influência da leguminosa na qualidade da silagem de milho. Arquivos da Escola de Veterinária da UFMG, Belo Horizonte, v. 32, n. 3, p. 415-420, 1980.

CASELA, C. R.; BORGONOVI, R. A.; SCHAFFERT, R. E.; SANTOS, F. G. Cultivares de sorgo. Informe Agropecuário, Belo Horizonte, v. 12, n. 144, p. 40-43, dez. 1986.

COMISSÃO DE FERTILIDADE DO SOLO DO ESTADO DE MINAS GERAIS. Recomendações para o uso de corretivos e fertilizantes em Minas Gerais. $4^{\mathrm{a}}$ aproximação. Lavras, 1989. 159 p.

COSTA, N. de L.; AZEVEDO, D. M. P. de. Produção e composição química de cultivares de sorgo forrageiro. In: CONGRESSO NACIONAL DE MILHO E SORGO, 21., 1996, Londrina. Resumos... Londrina: IAPAR, 1996. p. 216.

EVANGELISTA, A. R. Consórcio milho-soja e sorgo-soja: rendimento forrageiro, qualidade e valor nutritivo das silagens. 1986. 77 p. Tese (Doutorado em Zootecnia) - Universidade Federal de Viçosa, Viçosa.

FEHR, W. R.; CAVINESS, C. E. Stage of soybean development. Ames: Iowa State University, 1977. 12 p. (Special Report, 80).

HARBERS, L. H.; SHIRLEY, J. E.; BOLSEN, K. K.; HARTADI, H. Evaluation of interseeded grain sorghum and soybean silage for mid-lactation dairy cows. Journal of Dairy Science, Champaign, v. 75, p. 204, 1992. (Supplement 1).

LISEU, L. C. Curva de produção, composição química, digestibilidade "in vitro" e taxa de fermentação do sorgo. 1981. 96 p. Dissertação (Mestrado em Zootecnia) - Escola Superior de Agricultura de Lavras, Lavras.

MALAVOLTA, E.; VITTI, G. C.; OLIVEIRA, S. A. Avaliação do estado nutricional das plantas: princípios e aplicações. Piracicaba: [s.n.], 1989. 201 p. 
OLIVEIRA, A. F. de. Efeito da associação de cultivares de milho (Zea mays L.) e soja | Glycine max (L.) Merrill| no rendimento e valor nutritivo da forragem. 1986. 74 p. Dissertação (Mestrado em Fitotecnia) - Escola Superior de Agricultura de Lavras, Lavras.

OLIVIERA, J. M. de. Rendimento, qualidade da forragem e valor nutritivo das silagens de sorgo (Sorghum bicolor (L.) Moench), forrageiro e granífero, consorciado com soja (Glycine max (L.) Merrill). 1989. 57 p. Tese (Doutorado em Zootecnia) - Universidade Federal de Viçosa, Viçosa.

PEREIRA, O. G. Produtividade do milho ( $\mathrm{Zea}$ mays L.), do sorgo (Sorghum bicolor (L.) Moench), da aveia (Avena sativa), do milheto (Pennisetum americanum L.) e do híbrido ( $S$. bicolor x $S$. sudanense), e os respectivos valores nutritivos sob a forma de silagem e verde picado. $1991.86 \mathrm{p}$. Dissertação (Mestrado em Zootecnia) - Universidade Federal de Viçosa, Viçosa.

PUPO, N. I. H. Conservação de forragens. In:

Manual de pastagens e forrageiras: formação, conservação, utilização. Campinas: Instituto Campineiro de Ensino Agrícola, 1995. Cap. 14, p. 252-303.
REZENDE, P. M. de. Capacidade competitiva de cultivares de milho e soja consorciados em função da produção de grãos e forragem. 1995.154 p. Tese (Doutorado em Fitotecnia) - Universidade Federal de Lavras, Lavras.

REZENDE, P. M. de; TAKAHASHI, S. Maximização da exploração da soja [Glycine $\max$ (L.) Merrill]. IX. Efeito do sistema de cortes na seleção de cultivares para produção de feno. Ciência e Prática, Lavras, v. 14, n. 1. p. 44-55, jan./abr. 1990.

SILVA, A. G. Produção de forragem de cultivares de sorgo e soja, consorciadas na linha, em dois sistemas de corte. 1998. 80 p. Dissertação (Mestrado em Fitotecnia) - Universidade Federal de Lavras, Lavras.

SOOD, B. R.; SHARMA, V. K. Effect of nitrogen level on the yield and quality of forage sorghum (Sorghum bicolor) intercropped with legumes. Indian Journal of Agronomy, New Delhi, v. 37, n. 4, p. 642644, Dec. 1992. 